\title{
Comparison of Chilled ceiling and Mixing ventilation assisted by intermittent personalized ventilation: Thermal comfort and Energy savings
}

\author{
D. Al Assaad ${ }^{1}$, K. Ghali ${ }^{1}$ and N. Ghaddar ${ }^{1}$ \\ ${ }^{1}$ Department of Mechanical Engineering \\ American University of Beirut \\ P.O. Box 11-0236, Beirut 1107-2020, Lebanon \\ Phone/Fax number: +961 1 340460, Ext.3438, e-mail: ka04@aub.edu.lb
}

\begin{abstract}
The integration of intermittent personalized ventilation in office spaces equipped with chilled ceiling and mixing ventilation has been proven to enhance comfort and provide energy savings. However, the performance of the intermittent personalized ventilation has not been compared between both systems. This is important to see under which system the intermittent personalized ventilation performs best. In this work, two office spaces equipped with a chilled ceiling/mixing ventilation coupled with intermittent personalized ventilation were modelled using validated CFD models. The intermittent jet was supplied towards an infected occupant at an average flow rate of $7.5 \mathrm{~L} / \mathrm{s}$. The frequency of the intermittent PV was varied in each case. It was found that the intermittent personalized ventilator provided better thermal comfort in the case of chilled ceiling under neural to warm conditions (14\% increase compared to MV systems). However, twice as much energy savings were obtained in the case of mixing ventilation than chilled ceilings. Therefore, it is better off to operate intermittent PVU under MV systems.
\end{abstract}

\section{Key words}

Personalized ventilation, chilled ceiling, mixing ventilation, thermal comfort, energy savings

\section{Introduction}

Heating ventilation and air conditioning (HVAC) systems are integrated within building envelopes to ensure the wellbeing of occupants by responding to their thermal comfort needs [1]. There are many types of HVAC systems that can be installed in indoor spaces, each characterized by advantages as well as their shortcomings. Two conventional systems are the mixing ventilation (MV) system and the chilled ceiling (CC) system.

In MV systems, thermal comfort is generally met by bringing air room temperature to adequate levels through mixing of the supplied air with the room air and also by displacement of the warm and polluted air and replacing it with cool and clean air. To meet comfort requirements, a large percentage of cool fresh air should be brought into the space which entails high energy consumption. In other words, requirements are met in MV systems by maintaining the space at a constant temperature and a homogenous air quality by a mixed fresh-return air distribution. In such design, the individual environmental preference is not accommodated since room temperature is controlled by single thermostat. This may lead in an open space to the failure in satisfying the thermal comfort needs of all occupants [2,3].

On the other hand, CC systems usually consist of a metal panel installed at ceiling height and cooled by chilled water circulating in pipes. They provide thermal comfort for occupants through radiative and convective heat exchange with heated surfaces and are characterized by their quiet operation [4]. Using computational fluid dynamics (CFD), Catalina et al. [5] modeled a test room equipped with a $\mathrm{CC}$ for thermal comfort investigation. Their results showed that small vertical temperature gradients were found in the room as well as small momentum and good values of thermal comfort. CC are also beneficial in terms of saving energy. In fact, the heat removed from the occupant by the $\mathrm{CC}$ allows it to maintain the room at higher ambient temperatures than typical HVAC systems for similar comfort. This reduces energy costs by decreasing the cooling load. Numerical simulations of rooms equipped with CC showed a $10 \%$ reduction in energy consumption [6]. Even though the $\mathrm{CC}$ is an efficient system in providing thermal comfort, it has its disadvantages. In fact, CC systems can only remove a limited load from the space, risk condensation at the ceiling level and can compromise IAQ since they don't bring in fresh air into the space.

Consequently, MV and CC systems assure macroclimates characterized by recirculation zones and increased turbulence. sDue to these shortcomings, MV and $\mathrm{CC}$ systems cannot function as standalone systems and need to be assisted by additional HVAC units that can compensate their shortcomings. A viable option are the personalized ventilation units (PVU) which are localized energy efficient HVAC systems. PVU target the personal environment of the occupant by supplying cool fresh air directly to the breathing zone [7]. Hence, PVU can enhance thermal comfort as well as provide good breathable air quality. Moreover, these systems are cheap 
and can be either integrated into the office furniture or constitute personal systems that can be incorporated into human clothing. PVU systems exist in many configurations, which have been developed and studied in literature through experiments or numerical modeling (desk mounted, ceiling mounted) [8, 9]. Cermak et al. [10] tested experimentally two types of PVU (vertical desk grills and round movable panels) in conjunction with a MV system in an office space occupied by two breathing thermal manikins. Their results showed that PV was able to enhance IAQ in the BZ as well thermal comfort while the mixed macroclimate was contaminated. In a numerical study, Makhoul et al. [8] applied the concept of coaxial jets to ceiling PV in offices. They reported that the system was able to improve thermal comfort and IAQ in the occupant microenvironment compared to single PVU jets as well as reduce energy consumption.

In more recent applications, the cool fresh air supplied by the PVU was modified by fluctuating the supply flow rate between a minimum and a maximum at a certain characteristic frequency [11]. The intermittency of the PVU system was found to improve thermal comfort compared to steady flow rates. Ghali et al. [12] performed outdoor experiments on human subjects and reported that the average thermal comfort improved with the change in wind frequency. Furthermore, providing airflow intermittently can help decrease PV energy costs even further by reducing the amount of fresh air to be cooled by the system and lowering the fans' power consumption as reported by Kabanshi et al. [13] who used ceiling mounted Air Jet Diffusers (AJD) supplying dynamic airflow in an ON-OFF pattern. Al-Assaad et al. [14, 15] coupled intermittent PVU with $\mathrm{MV}$ and $\mathrm{CC}$ and proved that comfort was enhanced and that energy savings can be achieved compared to a steady PVU. However, the performance of intermittent PVU was not compared between the systems as they have similar microclimate characteristics.

In this study, two office spaces conditioned by MV and CC systems and coupled with a desk mounted intermittent PVU are considered. The ability of the intermittent PVU in providing comfort was studied using experimentally validated transient 3D CFD models coupled with bio-heat models. A parametric study is then conducted where the frequency of the intermittent PVU was varied to investigate its effect on comfort. Energy savings were also assessed. The performance of both systems were compared and a conclusion is made on the applicability of intermittent PVU in indoor spaces.

\section{Problem description}

The study considers two typical office spaces of dimensions $3.4 \mathrm{~m} \times 3.4 \mathrm{~m} \times 2.8 \mathrm{~m}$. Both offices are equipped with a workstation and an occupant represented by a thermal manikin. They are also equipped with a wooden door $(2 \mathrm{~m} \times 1 \mathrm{~m})$ and the office is considered to have small apertures $(0.5 \mathrm{~m} \times 0.6 \mathrm{~m})$. Several layers of brick and concrete are considered to constitute the room walls. The inner layer is made out of a Gypsum board having a thermal conductivity of $0.161 \mathrm{~W} / \mathrm{m} . \mathrm{K}$. The total load to be removed is a typical load of $40 \mathrm{~W} / \mathrm{m}^{2}$ due to computer, lighting, occupants [16]. The first office is conditioned by a CC system. The MV and CC system are coupled with an intermittent PVU system. The PVU nozzle is mounted on the desk, has a diameter outlet of 5 $\mathrm{cm}$ and located at $40 \mathrm{~cm}$ from the occupant. Figure 1 illustrates the considered spaces. Each of the PVU and MV have their own air handling unit (AHU) supplying $100 \%$ fresh filtered air. The concentration of active and passive particles $\left(\mathrm{NO}_{2}, \mathrm{CO} \ldots\right)$ in the supplied air is negligible and the concentration in $\mathrm{CO}_{2}$ is $450 \mathrm{ppm}$. The intermittent PVU characterized by a sinusoidal flow rate supplied at a certain frequency $f$ and an average flow rate. The minimum PVU flow rate should guarantee that the fresh air penetrates the occupant's free convective flow and reaches the BZ. The average flow rate considered in this study is $7.5 \mathrm{~L} / \mathrm{s}$ with a minimum of $1 \mathrm{~L} / \mathrm{s}$. The frequency range is $[0.3 \mathrm{~Hz}-1 \mathrm{~Hz}]$, which is the typical frequency range felt by occupants indoors.

a)

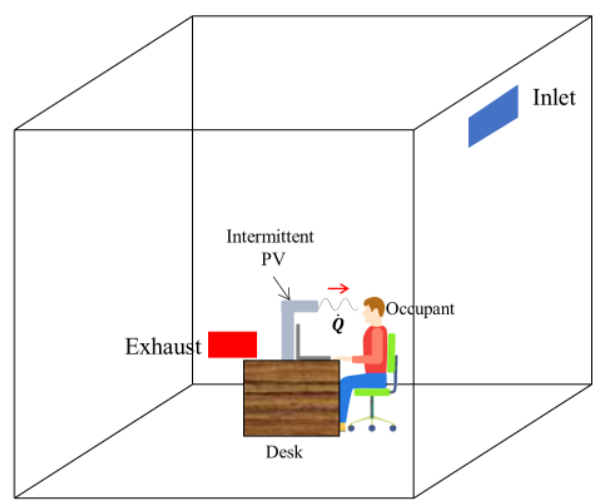

b)

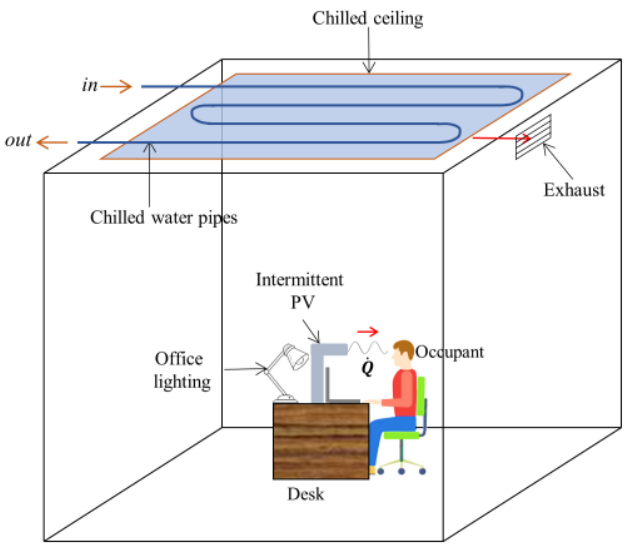

Fig. 1. Schematic of the office space with the intermittent PVU coupled with: a) MV system, b) CC system.

In order to assess these effects on thermal comfort, a transient bio heat model which can capture the time variations of skin temperatures is needed. The transient bio-head model of Othmani et al. [17] is used and is coupled with the CFD model in ANSYS to predict the thermal response of the occupant based on modeled physiology. The bio-heat model divides the body into 11 segments (head, chest, back, abdomen, back, buttocks, upper arm, lower arm, thighs, calves, and feet), it takes as input the environmental conditions including ambient air temperature and the convective heat transfer coefficients 
near each body segments and outputs the segmental skin temperatures. In order to couple the CFD and bio-heat models, the thermal manikin was initiated with typical skin temperature. The ambient skin temperatures as well as convective heat transfer coefficients were used as input from the CFD model to the transient bio-heat model. For the face segment subject to the transient PV airflow, the ambient skin temperatures and convective heat transfer coefficients are transient while for the other segments, they remain constant. After obtaining the skin temperatures, they were taken as input boundary conditions to the thermal manikin in the CFD model. The latter was then simulated until convergence is reached once more. This coupling algorithm was iterated several times until the relative error between two iterations is smaller than $10^{-3}$. After convergence, the output skin temperatures, core temperatures and their rate of change are taken as input into the sensation and comfort models of Zhang et al. [18 20]. In these models, Zhang et al. [18 - 20] performed intensive human subjects' experiments to develop a sensation and comfort scales ranging from -4 (very cold, very uncomfortable respectively) to +4 (very hot, very comfortable, respectively).

\section{CFD model}

In this work, there are complex airflow field behavior that are taking place due to the presence of the MV, CC and the PVU systems. In fact the MV establishes a complex flow with recirculation zones and mixing. The $\mathrm{CC}$ establishes a gradient of temperature in the space which leads to unstable stratification and buoyancy which in turn results in high turbulence intensities in the space. Moreover, the transient PVU jet is another factor which increases turbulence in the microenvironment surrounding the occupant. In addition, there are several heat sources in the space giving rise to thermal plumes. This affects the airflow field variables such as velocity, temperature, turbulence intensity. Consequently, a 3D computational fluid dynamics model (CFD) is needed to resolve for these different fields. A CFD tool is used to precisely resolve the different variables. The commercial software ANSYS Fluent [21] was used to solve the momentum, energy equations, pressure velocity coupling as well as the turbulence, dissipation rate equations and discrete phase models... For exact predictions of flow behavior, the space should be appropriately meshed (Fig 2). Therefore, inflation layers are created around the boundaries such that the range of the dimensionless wall number $y^{+}$is $[0.8-4]$ [22]. The considered space is meshed into tetrahedral elements with face sizing applied at the boundaries (thermal manikin: $1.5 \mathrm{~cm}$, walls: $2 \mathrm{~cm}$. The MV+PVU mesh has 1,056,484 elements and 303,533 nodes. The CC+PVU mesh had 5119220 elements with 951942 nodes. These meshes ensured a grid independent solution (maximum relative error of less than $5 \%$ on velocity measurements). a)
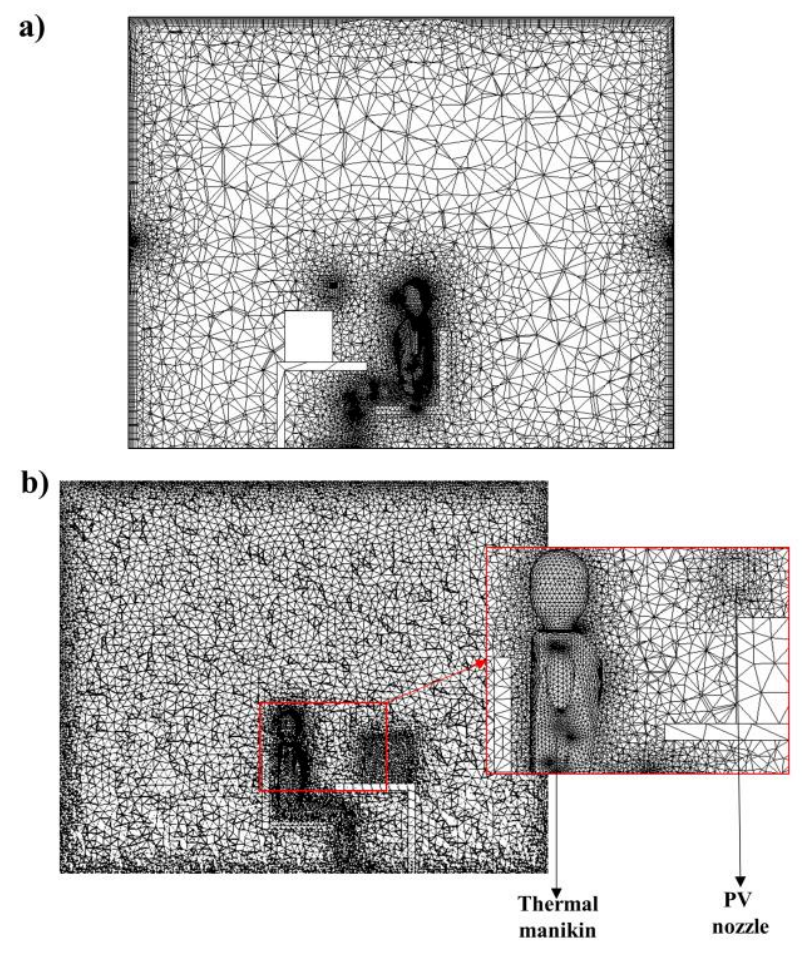

Fig. 2. Illustration of the space meshes in ANSYS Fluent, for a) the MV system and b) the CC system.

Due to the turbulence created by the intermittent PVU jet, MV and the CC, the $R N G k-\varepsilon$ model was used to model turbulence [17]. Due to small density variations, the Boussinesq approximation is used to account for buoyancy effects. The $\mathrm{S} 2 \mathrm{~S}$ radiation model is implemented to account for the radiation between $\mathrm{CC}$ and heated surfaces. The discretization schemes for the different variables (momentum, energy, $k, \varepsilon$, species...) are presented in Table 1 . Numerical convergence is reached for scaled residuals of less than $10^{-5}$ for all quantities except energy where it should be less than $10^{-7}$.

Table 1. Flow field variables and the different discretization schemes.

\begin{tabular}{|l|c|}
\hline \multicolumn{1}{|c|}{ Flow Field variables } & Scheme \\
\hline $\begin{array}{l}\text { momentum, energy, k, } \varepsilon \text { and } \\
\text { turbulence equations, species } \\
\text { transport }\end{array}$ & second order upwind scheme \\
\hline pressure equation & "PRESTO!" scheme \\
\hline Transient term & second order implicit time \\
& stepping scheme, time step of \\
& 0.05 seconds \\
\hline Pressure velocity coupling & PISO scheme \\
\hline
\end{tabular}

\section{Results and discussion}

The CFD models of the intermittent PVU+CC system were previously validated in the work of $\mathrm{Al}$ Assaad et al. $[14,15]$. The model is simulated for three typical frequencies found in indoor spaces $(0.3 \mathrm{~Hz}, 0.5 \mathrm{~Hz}, 1$ $\mathrm{Hz}$ ). The MV and CC assure temperatures of $26^{\circ} \mathrm{C}$ in the ambient environment, which is slightly warm. The PVU supply temperature is set to $22^{\circ} \mathrm{C}$. A temperature difference of $4^{\circ} \mathrm{C}$ is assured between the PVU and the 
space to limit temperature asymmetry between the different body segments and hence avoid draft discomfort.

Table 2 represents the variation of overall thermal comfort (OTC) (predicted by the comfort model of Zhang et al. [18-20]), as a function of frequency for an average PVU flowrate of $7.5 \mathrm{~L} / \mathrm{s}$. It can be seen that with the increase in frequency in both cases, overall thermal comfort increased. This is due to the amplified turbulence levels with increased with frequency, which enhanced the rate of change of skin temperatures and hence heat losses from the skin. Increased heat losses were favorable in these warm ambient conditions, which improved thermal comfort. The contours of temperature for both MV and $\mathrm{CC}$ can be seen in Fig 3 and 4 respectively. When comparing between the comfort levels of MV and CC systems, it can be seen that the intermittent PVU provided better comfort in CC systems. In fact, OTC values were $14 \%$ higher in the case of the intermittent PVU with CC compared to MV. This can be explained the turbulence levels in the occupant microclimate. In fact, turbulence levels in the CC occupant microclimate were smaller than that in the MV macroclimate. In fact, for a PVU frequency of $0.5 \mathrm{~Hz}$, in the case of the $\mathrm{CC}$ space, turbulence intensities reached maximums of $39 \%$ at the $\mathrm{BZ}$ while in the case of $\mathrm{MV}$, turbulence intensities reached maximums of $50 \%$ at the BZ. Higher turbulence levels means increased heat losses from the skin in the MV space compared to the CC space. Therefore, heat losses in MV spaces started to surpass their threshold values of comfort for this macroclimate temperature of $26^{\circ} \mathrm{C}$. Consequently, for each macroclimate temperature, a threshold value for turbulence intensities, and thus sensible heat losses from the skin exists that assures maximal comfort. This value increases with even warmer indoor environments. Subsequently, in terms of thermal comfort in warm indoor environments of $26^{\circ} \mathrm{C}$, the intermittent PVU works best under CC systems.

Table 2. Overall thermal comfort at different PV frequencies at an average flow rate $7.5 \mathrm{~L} / \mathrm{s}$

\begin{tabular}{|c|c|c|}
\hline \multicolumn{2}{|c|}{$\boldsymbol{T}_{\boldsymbol{a}}=\mathbf{2 6}{ }^{\circ} \boldsymbol{C}, \boldsymbol{P V}$ jet $\boldsymbol{T}_{\boldsymbol{P V}}=22^{\circ} \boldsymbol{C}, \boldsymbol{R H}=\mathbf{5 0 \%}$} \\
\hline $\begin{array}{c}\text { PV frequency } \\
(\mathrm{Hz})\end{array}$ & MV system & CC system \\
\hline 0.3 & 0.341 & 0.386 \\
\hline 0.5 & 0.4966 & 0.578 \\
\hline 1 & 1.015 & 1.181 \\
\hline
\end{tabular}
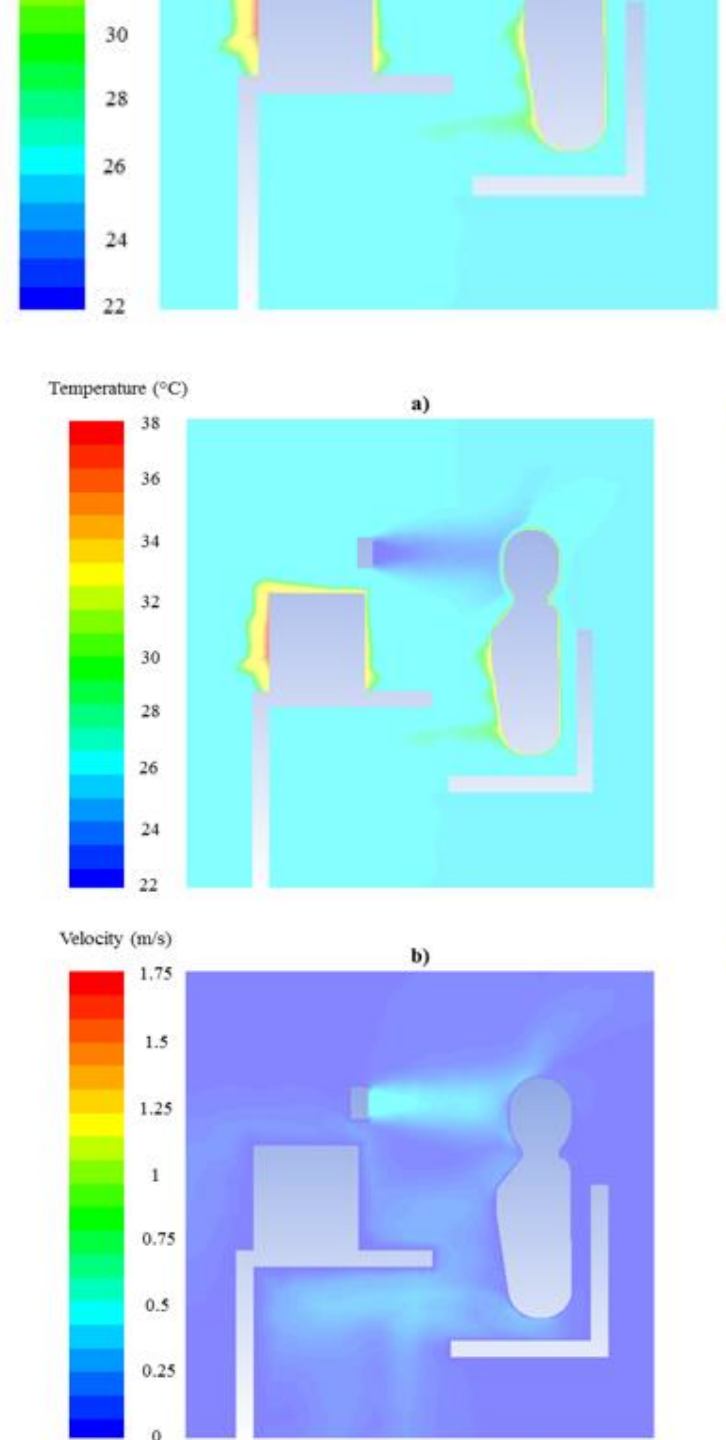

Fig. 3 Illustration of temperature and velocity contours for the MV case at an average PVU flow rate of $7.5 \mathrm{~L} / \mathrm{s}$ for a frequency of $0.5 \mathrm{~Hz}$

In order to calculate the energy savings of the intermittent $\mathrm{PVU}+\mathrm{CC} / \mathrm{MV}$ system, the fan power consumption as well as the cooling capacity of an intermittent PVU should be calculated and compared to a steady case. The reference steady state condition in the case of MV is a steady PVU flow rate of $9 \mathrm{~L} / \mathrm{s}$ and in the case of CC, a PVU flow rate of $7.5 \mathrm{~L} / \mathrm{s}$ that provides similar comfort. The correlation of Keblawi et al. [23] was used to calculate fan power consumption:

$P_{\text {fan }}=P_{\text {ref }}\left(\frac{m_{\text {fan }}^{*}}{m_{\text {fangef }}^{*}}\right)^{3}$

Where $m_{f a n}$ is the fan mass flow rate, $P_{f a n}$ is the fan power consumption, $P_{\text {ref }}$ and $m_{\text {fangref }}$ are the nominal power consumption and mass flow rate respectively for steady state PVU operation. To account for time variation, the power was averaged over one period. It was found that a transient fan operation $(2 \mathrm{~W})$ was slightly higher than a steady case $(1.62 \mathrm{~W})$. However, the decrease in cooling capacity was more significant than the increase in fan power consumption between transient and steady state PVU operation. Therefore, a transient PVU system operating at an average flow rate of $7.5 \mathrm{~L} / \mathrm{s}$ provided energy savings of $16.1 \%$ and $7.5 \%$ in the case of MV and CC respectively. 


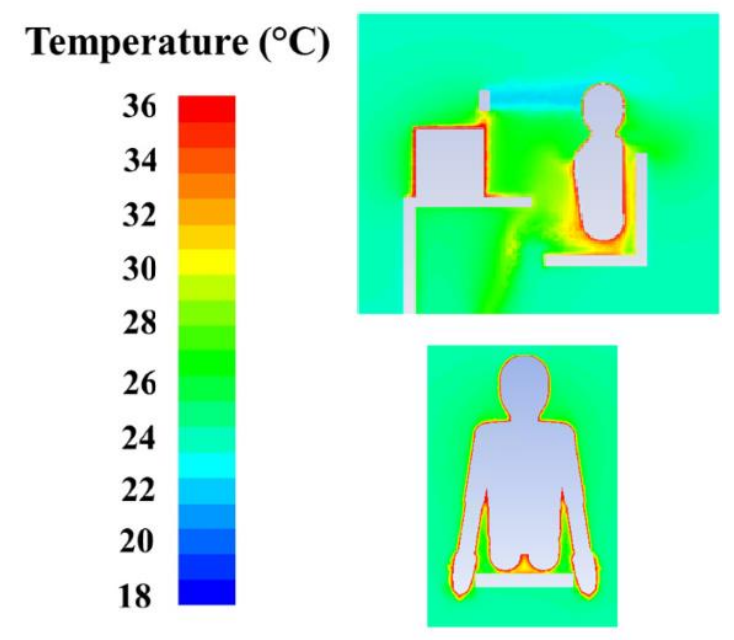

Fig. 4. Illustration of temperature contours for the $\mathrm{CC}$ case at an average PVU flow rate of $7.5 \mathrm{~L} / \mathrm{s}$ for a frequency of $0.5 \mathrm{~Hz}$.

\section{Conclusion}

A transient validated 3D CFD model was simulated to conduct a study on intermittent PVU assisting conventional $\mathrm{CC}$ and $\mathrm{MV}$ systems. It was found that increasing frequency enhanced thermal comfort in the case of $\mathrm{CC}$ and MV systems. Note that $14 \%$ better comfort was obtained in the case of CC compared to MV due to smaller turbulence levels in the $\mathrm{CC}$ space. This was favorable in warm ambient conditions due to increased heat losses. However, twice as much energy savings were obtained in the case of MV systems. Therefore, it is better off to operate the intermittent PVU with MV systems, since it provides comparable levels of comfort to $\mathrm{CC}$ systems while assuring higher energy savings.

\section{References}

[1] Wang, S., \& Ma, Z. (2008). Supervisory and optimal control of building HVAC systems: A review. $H V A C \& R$ Research, 14(1), 3-32.

[2] Behne, M. (1999). Indoor air quality in rooms with cooled ceilings.: Mixing ventilation or rather displacement ventilation?. Energy and Buildings, 30(2), 155-166.

[3] Noh, K. C., Jang, J. S., \& Oh, M. D. (2007). Thermal comfort and indoor air quality in the lecture room with 4 way cassette air-conditioner and mixing ventilation system. Building and Environment, 42(2), 689-698.

[4] Novoselac, A., \& Srebric, J. (2002). A critical review on the performance and design of combined cooled ceiling and displacement ventilation systems. Energy and buildings, 34(5), 497-509.

[5] Catalina, T., Virgone, J., \& Kuznik, F. (2009). Evaluation of thermal comfort using combined CFD and experimentation study in a test room equipped with a cooling ceiling. Building and environment, 44(8), 17401750 .
[6] Carbonnier, K., Higgins, C., Bauman, F., Karmann, C., Raftery, P., Schiavon, S., \& Graham, L. T. (2017). Energy Use, Occupant Surveys and Case Study Summary: Radiant Cooling and Heating in Commercial Buildings.

[7] Melikov, A. K. (2016). Advanced air distribution: improving health and comfort while reducing energy use. Indoor air, 26(1), 112-124.

[8] Makhoul, A., Ghali, K., \& Ghaddar, N. (2013). Desk fans for the control of the convection flow around occupants using ceiling mounted personalized ventilation. Building and Environment, 59, 336-348.

[9] Gao, R., Wang, C., Li, A., Yu, S., \& Deng, B. (2018). A novel targeted personalized ventilation system based on the shooting concept. Building and Environment, 135, 269-279.

[10] Cermak, R., Melikov, A. K., Forejt, L., \& Kovar, O. (2006). Performance of personalized ventilation in conjunction with mixing and displacement ventilation. Hvac\&R Research, 12(2), 295-311.

[11] Uğursal, A., \& Culp, C. H. (2013). The effect of temperature, metabolic rate and dynamic localized airflow on thermal comfort. Applied energy, 111, 64-73.

[12] Ghali, K., Ghaddar, N., \& Bizri, M. (2011). The influence of wind on outdoor thermal comfort in the city of Beirut: a theoretical and field study. $H V A C \& R$ Research, 17(5), 813-828.

[13] Kabanshi, A., Wigö, H., \& Sandberg, M. (2016). Experimental evaluation of an intermittent air supply system-Part 1: thermal comfort and ventilation efficiency measurements. Building and Environment, 95, 240-250.

[14] Al Assaad, D., Ghali, K., \& Ghaddar, N. (2018). Effectiveness of intermittent personalized ventilation assisting a chilled ceiling for enhanced thermal comfort and acceptable indoor air quality. Building and Environment, 144, 9-22.

[15] Al Assaad, D., Habchi, C., Ghali, K., \& Ghaddar, N. (2018). Effectiveness of intermittent personalized ventilation in protecting occupant from indoor particles. Building and Environment, 128, 22-32

[16] Hweij, W. A., Ghaddar, N., Ghali, K., \& Habchi, C. (2016). Optimized performance of displacement ventilation aided with chair fans for comfort and indoor air quality. Energy and Buildings, 127, 907-919.

[17] Al-Othmani, M., Ghaddar, N., \& Ghali, K. (2008). A multi-segmented human bioheat model for transient and asymmetric radiative environments. International Journal of Heat and Mass Transfer, 51(23-24), 55225533. 
[18] Arens, E., Zhang, H., \& Huizenga, C. (2006). Partialand whole-body thermal sensation and comfort-Part II: Non-uniform environmental conditions. Journal of thermal Biology, 31(1-2), 60-66.

[19] Zhang, H., Arens, E., Huizenga, C., \& Han, T. (2010). Thermal sensation and comfort models for non-uniform and transient environments: Part I: Local sensation of individual body parts. Building and Environment, 45(2), 380-388.

[20] Zhang, H., Arens, E., Huizenga, C., \& Han, T. (2010). Thermal sensation and comfort models for non-uniform and transient environments, part III: Whole-body sensation and comfort. Building and Environment, 45(2), 399-410.

[21] ANSYS Blog | Engineering Simulation Software News and Insights, (n.d.). https://www.ansys.com/blog/tag/ANSYS HFSS 3D (accessed November 14, 2018).

[22] Al Assaad, D., Ghali, K., Ghaddar, N., \& Habchi, C. (2017). Mixing ventilation coupled with personalized sinusoidal ventilation: Optimal frequency and flow rate for acceptable air quality. Energy and Buildings, 154, 569580 .

[23] Keblawi, A., Ghaddar, N., Ghali, K., \& Jensen, L. (2009). Chilled ceiling displacement ventilation design charts correlations to employ in optimized system operation for feasible load ranges. Energy and Buildings, 41(11), 1155-1164. 